Check for updates

Cite this: RSC Adv., 2018, 8, 8828

Received 12th January 2018 Accepted 16th February 2018

DOI: $10.1039 / c 8 r a 00347 e$

rsc.li/rsc-advances

\section{D nanorhombus nickel nitride as stable and cost- effective counter electrodes for dye-sensitized solar cells and supercapacitor applications}

Saradh Prasad, (DD ab G. Durai, ${ }^{c}$ D. Devaraj, ${ }^{\text {a }}$ Mohamad Saleh AlSalhi, ${ }^{\text {bb }}$ J. Theerthagiri, ${ }^{c}$ Prabhakarn Arunachalam, iD d M. Gurulakshmi, ${ }^{e}$ M. Raghavender iD e and P. Kuppusamic

Transition metal nitride based materials have attracted significant interest owing to their excellent properties and multiple applications in the field of electrochemical energy conversion and storage devices. Herein we synthesize 3D nanorhombus nickel nitride $\left(\mathrm{Ni}_{3} \mathrm{~N}\right)$ thin films by adopting a reactive radio frequency magnetron sputtering process. The as-deposited 3D nano rhombus $\mathrm{Ni}_{3} \mathrm{~N}$ thin films were utilized as costeffective electrodes in the fabrication of supercapacitors (SCs) and dye-sensitized solar cells (DSSCs). The structure, phase formation, surface morphology and elemental composition of the as-deposited $\mathrm{Ni}_{3} \mathrm{~N}$ thin films were characterized by $\mathrm{X}$-ray diffraction (XRD), field emission scanning electron microscopy (FESEM), energy-dispersive $X$-ray spectroscopy (EDS) and atomic force microscopy (AFM). The electrochemical supercapacitive performance of the $\mathrm{Ni}_{3} \mathrm{~N}$ thin films was examined by cyclic voltammetry (CV) and galvanostatic charge-discharge (GCD) techniques, in $3 \mathrm{M} \mathrm{KOH}$ supporting electrolyte. The areal capacitance of the $\mathrm{Ni}_{3} \mathrm{~N}$ thin film electrode obtained from $\mathrm{CV}$ analysis was $319.5 \mathrm{mF} \mathrm{cm}^{-2}$ at a lower scan rate of $10 \mathrm{mV} \mathrm{s}^{-1}$. Meanwhile, the $\mathrm{Ni}_{3} \mathrm{~N}$ thin film showed an excellent cyclic stability and retained $93.7 \%$ efficiency of its initial capacitance after 2000 cycles at $100 \mathrm{mV} \mathrm{s}^{-1}$. Interestingly, the DSSCs fabricated with a $\mathrm{Ni}_{3} \mathrm{~N}$ CE showed a notable power energy conversion efficiency of $2.88 \%$ and remarkable stability. The prominent performance of the $\mathrm{Ni}_{3} \mathrm{~N}$ thin film was ascribed mainly due to good conductivity, high electrochemically active sites with excellent 3D nano rhombus structures and high electrocatalytic activity. Overall, these results demonstrate that the $\mathrm{Ni}_{3} \mathrm{~N}$ electrode is capable of being considered for efficient SCs and DSSCs. This investigation also offers an essential directive for the advancement of energy storage and conversion devices.

\section{Introduction}

The primary source of energy for our planet is solar radiation. The fossil fuels that are available today were created by photosynthesis of micro-plankton and other organisms millions of years ago. In addition, wind energy is created by the unequal heating of our planet by the sun. Conventional energy sources such as coal, fossil fuels and nuclear power are creating an

${ }^{a}$ Department of Electrical and Electronics Engineering, School of Electronics and Electrical Technology (SEET), Kalasalingam Academy of Research and Education (KARE), Krishnankoil, Virudhunagar 626126, Tamil Nadu, India. E-mail: deva230@ yahoo.com

${ }^{b}$ Research Chair on Laser Diagnosis of Cancers, Department of Physics and Astronomy, College of Science, King Saud University, 11451, Riyadh, Saudi Arabia. E-mail: malsalhy@gmail.com

${ }^{c}$ Centre of Excellence for Energy Research, Sathyabama Institute of Science and Technology (Deemed to be University), Chennai 600119, India

${ }^{d}$ Electrochemistry Research Group, Chemistry Department, College of Science, King Saud University, Riyadh, 11451, Saudi Arabia

${ }^{e}$ Department of Physics, Yogi Vemana University, Kadapa-516003, A.P., India energy crisis with environmental problems. Even hydropower dams are not free from green house emission. ${ }^{1}$ Increasing energy and environmental problems have urged researchers to focus on renewable energy resources. Solar energy is recognized as the most abundant energy source, which can rectify environmental and energy associated issues. Of the many types of solar cells, DSSCs are the cheapest, when compared to conventional silicon solar cells. However, DSSCs have shortcomings such as low PCE and stability. Moreover, the usage of platinum (Pt) and other noble metal counter electrodes (CE) account for a significant portion of DSSC manufacturing costs.

Design and development of alternative CEs from different materials have attracted immense research interest in recent years. Many types of CEs have been investigated as alternatives for Pt CEs, such as transition metals (oxides, sulfides, and nitrides), ${ }^{2-5}$ carbon based materials (nanotubes, ${ }^{6}$ graphene oxide, ${ }^{7} \mathrm{C}_{60}, \mathrm{C}_{71}$, and PCBM), ${ }^{\mathbf{8} 9}$ and conjugated-polymers. ${ }^{\mathbf{1 0 - 1 2}}$ The CE material must possess a superior conductivity to enable rapid transportation of electrons and robust electrocatalytic activity to reduce triiodide ions, which should be comparable if 
not surpass Pt CEs. Several metal oxides have been examined for photo and electrocatalytic activity, some of which are outlined below, and a one-step synthesis of a $\mathrm{BiFeWO}_{6} / \mathrm{BiOI}$ nanocomposite was investigated for photochemical activity by Malathi et al. ${ }^{13}$ Highly porous cobalt hydroxide (meso-Co-OH) was found to be a cost-effective $\mathrm{CE}$ for efficient oxygen evolution reactions with the advantage that the material can be synthesized using a simple precipitation method. ${ }^{14}$ Recently, transition metal sulfides and graphitic carbon nitrides have been extensively explored as catalytic materials for photoelectrochemical applications. ${ }^{15-17}$

In particular, transition metal nitride (TMN) based materials have high electrocatalytic activity which arises from a precious metal-like modified electronic cloud structure, due to this it has found a vast number of applications such as in (a) lithium ion batteries, $^{18}$ (b) electrocatalytic applications ${ }^{\mathbf{1 9 , 2 0}}$ (like hydrogen production, ${ }^{21}$ hydrogen and oxygen evolution reactions, ${ }^{22,23}$ solar cells, supercapacitors and many more) and (c) magnetic particles. ${ }^{24}$ TMNs have attracted a lot of research, and a few of them are listed below. MoN atomic size thin nanosheets were fabricated by Xia et al. ${ }^{25}$ TiN showed inherently better electrocatalytic activity. Many other nitride CEs have shown better activity than their oxide or pure form CEs. ${ }^{6}$ A simple two step, solid state reaction was used to synthesise cobalt molybdenum nitride $\left(\mathrm{Co}_{0.6} \mathrm{M}_{1.4} \mathrm{~N}_{2}\right)$ which is able to show excellent hydrogen evolution reaction (HER) activity in acidic conditions. ${ }^{26}$ Nickel is one of Earth's abundant materials, and nickel based CE systems have been studied previously by various groups (NiO, NiS etc. $),{ }^{27,28}$ with excellent HER activity of $\mathrm{NiMoN}_{x} / \mathrm{C}$ being reported by Chen et al. ${ }^{29}$

Previously, $\mathrm{Ni}_{3} \mathrm{~N}$ with a sponge-like structure was reported for electrocatalytic activity, but in this work the $\mathrm{Ni}_{3} \mathrm{~N}$ was supported by being embedded in carbon-nitrogen material, which acts as a glue as well an electronic activator. ${ }^{30}$ The electrocatalytic activity of self-supported $\mathrm{Ni}_{3} \mathrm{~N}$ was investigated via three electrode alkaline hydrogen evolution. Unlike previous studies, in this work the $\mathrm{Ni}_{3} \mathrm{~N}$ was self-standing without the need for external support. ${ }^{31}$ Oxygen evolution reactions (OERs) were performed with a $\mathrm{CE}$ made of three nanolayers with carbon cloth at the bottom, above which a $\mathrm{Ni}_{3} \mathrm{~N}$ nanoarray was grown to support a 3D Ni carbonate layer. Due to this architecture superior electrocatalytic activity was shown, even with very small over drive voltages $\left(400 \mathrm{mV}\right.$ for $20 \mathrm{~mA} \mathrm{~cm}^{-2}$ in $1.0 \mathrm{M}$ $\mathrm{KHCO}_{3}$ (bulk pH: 8.3)). ${ }^{32}$ Very little work has been reported on DSSC $\mathrm{Ni}_{3} \mathrm{~N}$ CEs. In 2011, Park et al. used RF magnetron sputtering to deposit Ni-N films which were used as CEs for DSSCs (N719 dye as sensitizer and $\mathrm{I}_{3}{ }^{-} / \mathrm{I}^{-}$as redox couple). ${ }^{33}$ A surface nitrided layer was engaged as the CE in DSSCs by Q. W. Jiang et $a .^{27}$

$\mathrm{Ni}_{3} \mathrm{~N}$ can also be utilized as an electrode in supercapacitors. Here are a few studies that have used $\mathrm{Ni}-\mathrm{N}$ based materials for supercapacitor applications. Tiny $\mathrm{Ni}_{3} \mathrm{~N}$ nanoparticles firmly fastened to graphene sheets were used as electrodes in supercapacitors, the results showed that the specific capacitance could get as high as $2087.5 \mathrm{~F} \mathrm{~g}^{-1}$ (at $1 \mathrm{~A} \mathrm{~g}^{-1}$ ), with a superior energy density of $50.5 \mathrm{~W} \mathrm{~h} \mathrm{~kg}^{-1}$ at $800 \mathrm{~W} \mathrm{~kg}{ }^{-1} \cdot{ }^{34}$ A 3D nickel nitride $\left(\mathrm{Ni}_{3} \mathrm{~N}\right)$ nanosheet, consisting of a nanoflake structure was fabricated on carbon cloth via a hydrothermal process and had potential applications in the field of supercapacitors and flexible Li-ion batteries. ${ }^{35}$ It was found that high areal capacitance (around $655.1 \mathrm{mF} \mathrm{cm}{ }^{-2}$ ) could be achieved from $\mathrm{Cu}_{2}$ $\mathrm{NiSnS}_{4}$ nanoparticles embedded onto reduced 2D graphene. ${ }^{36}$

The development of $\mathrm{Ni}_{3} \mathrm{~N}$ based nanomaterial technology plays an important role in energy harvesting and storage, because of the properties and features of the materials used. A single-electrode system for both SCs and DSSCs would be beneficial for smart energy storage and conversion devices. According to knowledge on the similarity of the electronic structures of TMNs and noble metals, it can be expected that $\mathrm{Ni}_{3} \mathrm{~N}$ nitrides are capable of delivering Pt-like electrocatalytic performances. Consequently, an examination into the electrochemical behaviour of $\mathrm{Ni}_{3} \mathrm{~N}$ is very important not only for exciting scientific interest, but also for securing low-cost substitute electrode materials for supercapacitors as well as for Pt in DSSCs.

In this study we present self-supported 3D nano-rhombus (nano-diamond) shaped $\mathrm{Ni}_{3} \mathrm{~N}$ coated on FTO glass which serves as a CE in DSSCs and supercapacitors. To our knowledge this report is the first on $\mathrm{Ni}_{3} \mathrm{~N}$ 3D nano-rhombus structured films for solar cell and supercapacitor applications.

\section{Experimental section}

\subsection{Fabrication of nickel nitride $\left(\mathrm{Ni}_{3} \mathrm{~N}\right)$ thin films}

The nickel nitride $\left(\mathrm{Ni}_{3} \mathrm{~N}\right)$ thin films were fabricated with a single step reactive $\mathrm{RF}$ magnetron sputtering technique. To fabricate this $\mathrm{Ni}_{3} \mathrm{~N}$ thin film, a metallic nickel target (Ni) (Testbourne Ltd., UK, 2 inch dia., and $3 \mathrm{~mm}$ thickness) was used. Prior to the deposition, the substrates were cleaned ultra-sonically with water and acetone for 15 mins to remove the surface impurities. After the cleaning process, the substrates were loaded into the sputtering chamber and evacuated at the base pressure of $5 \times 10^{-3}$ mbar. During $\mathrm{Ni}_{3} \mathrm{~N}$ film deposition, the substrate temperature was kept at $200{ }^{\circ} \mathrm{C}$ with the argon (99.99\%) and nitrogen (99.99\%) gases held at 16 and $4 \mathrm{sccm}$ respectively and an RF power of 80 watts applied to the Ni target. During deposition the distance between the target and the substrate was maintained at $60 \mathrm{~mm}$. The $\mathrm{Ni}_{3} \mathrm{~N}$ deposition duration was $60 \mathrm{~min}$ and the thickness of the $\mathrm{Ni}_{3} \mathrm{~N}$ deposited films was about $400 \mathrm{~nm}$.

\subsection{Characterization of the films}

The structural and phase formation of the as-deposited $\mathrm{Ni}_{3} \mathrm{~N}$ thin film was observed via X-ray diffractometer (XRD-Bruker D8 Advance) measurements with $\mathrm{Cu}-\mathrm{K} \alpha$ radiation $(\lambda=0.154 \mathrm{~nm})$. The surface morphology of the $\mathrm{Ni}_{3} \mathrm{~N}$ thin film was inspected using FESEM (FESEM-Carl Zeiss, Supra 55) and the elemental composition was analysed by EDS equipped with FESEM. The surface roughness and topography of the $\mathrm{Ni}_{3} \mathrm{~N}$ thin film were examined using AFM (Bruker Dimension ICON).

\subsection{Fabrication of DSSCs}

The commercially available $\mathrm{TiO}_{2}$ coated FTO glass plates were treated with $40 \mathrm{mM} \mathrm{TiCl}_{4}$ solution for $30 \mathrm{~min}$ at $70{ }^{\circ} \mathrm{C}$, and then 
subjected to a sintering process at $500{ }^{\circ} \mathrm{C}$ for $30 \mathrm{~min}$. After cooling to $100{ }^{\circ} \mathrm{C}$, the resultant substrates were dipped in dye solution under dark conditions for a dipping time of $16 \mathrm{~h}$. N719 dye (Solaronix) was the dye used here, in a combination of tertbutanol/acetonitrile $(1 / 1 \mathrm{v} / \mathrm{v})$ at a concentration of $0.3 \mathrm{mM}$. The electrodes were then taken off and rinsed well with the appropriate solvents to remove the unanchored dye molecules from the surface of the $\mathrm{TiO}_{2}$ film, followed by drying under a $\mathrm{N}_{2}$ purge; the dye anchored active electrode area was $0.74 \mathrm{~cm}^{2}$. The DSSC test cells were assembled by similar methods as described in our recent report. ${ }^{37}$ The $\mathrm{Ni}_{3} \mathrm{~N}$ based tin films were formed through a RF magnetron sputtering deposition method and incorporated as CEs in DSSCs with a standard photoelectrode used for open cell configurations.

The electrolytes E1, E2 were injected through a pre-drilled hole in the $\mathrm{CE}$ and the holes sealed with Kapton adhesive tape. The details of E1 and E2 are given below.

E1: DMPII (0.5 M)-LiI (0.1 M) - I 2 (0.05 M)-GuNC (0.1 M)-4$t \mathrm{BP}(0.5 \mathrm{M})$ in methoxypropionitrile (MPN).

E2: DMPII (0.5 M)-LiI (0.1 M) - I 2 (0.05 M)-GuNC (0.1 M)-4$t \mathrm{BP}(0.5 \mathrm{M})$ in acetonitrile $(\mathrm{AcN})$.

The photocurrent density-voltage $(J-V)$ measurement of the open structured test cells was conducted via a xenon arc solar simulator (PEC-L01, Peccell Inc., Japan) with an AM 1.5 spectral filter and a sourcemeter (2401N Keithley Instruments Inc.), its light intensity was maintained at 1 Sun condition $(100 \mathrm{~mW}$ $\mathrm{cm}^{-2}$, AM 1.5 condition) using a calibrated mono-Sisolar cell. A mask of $0.25 \mathrm{~cm}^{2}(5 \mathrm{~mm} \times 5 \mathrm{~mm})$ was used for $J-V$ measurements. Electrochemical impedance spectroscopy (EIS) measurement was performed via IVIUMSTAT in the frequency range of $0.1 \mathrm{~Hz}$ to $1 \mathrm{MHz}$.

\section{Results and discussion}

\subsection{X-ray diffraction analysis}

The purity and phase formation of the as-deposited $\mathrm{Ni}_{3} \mathrm{~N}$ thin films were characterized using XRD spectroscopy and the obtained XRD pattern is displayed in Fig. 1. Diffraction peaks of $\mathrm{Ni}_{3} \mathrm{~N}$ are observed at $2 \theta$ values of $41.60^{\circ}$ and $70.37^{\circ}$ which correspond to (002) and (110) diffraction planes of $\mathrm{Ni}_{3} \mathrm{~N}$. The exhibited diffraction peaks match a hexagonal $\mathrm{Ni}_{3} \mathrm{~N}$ phase in concurrence with JCPDS card no. 89-7096. The average crystallite size, dislocation density and lattice strain were calculated according to previous reports. ${ }^{38,39}$ The crystallite size of $\mathrm{Ni}_{3} \mathrm{~N}$ was calculated from (002) reflections and the obtained crystallite size of the $\mathrm{Ni}_{3} \mathrm{~N}$ thin film is about $28.73 \mathrm{~nm}$, the dislocation density $(\delta)$ is $1.2115 \times 10^{15}$ lines per $\mathrm{m}^{2}$ and the calculated lattice strain $(\varepsilon)$ is 0.003401 .

\subsection{Morphology and elemental analysis}

The surface morphology and elemental composition of the asmade $\mathrm{Ni}_{3} \mathrm{~N}$ thin film were analysed using FESEM equipped with EDS. Fig. 2 represents the FESEM image and EDS spectrum of $\mathrm{Ni}_{3} \mathrm{~N}$ thin film with consequent elemental mapping for $\mathrm{Ni}$ and $\mathrm{N}$. The FESEM analysis clearly shows that the exhibited surface morphology of these $\mathrm{Ni}_{3} \mathrm{~N}$ thin films is a $3 \mathrm{D}$ nano

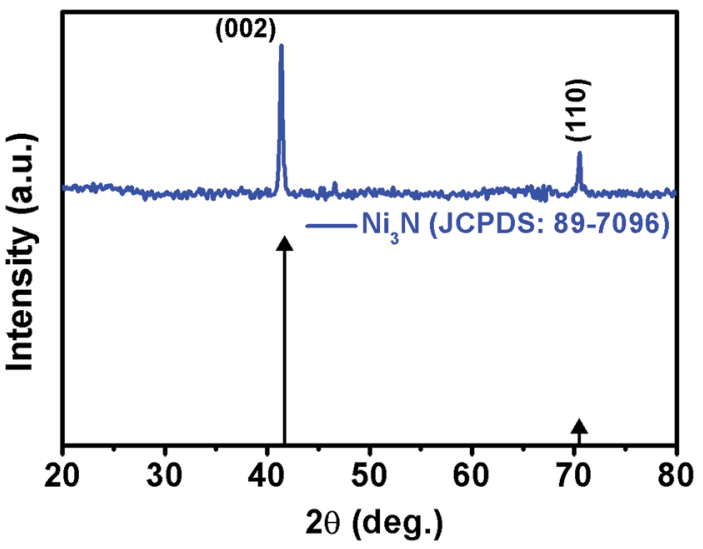

Fig. 1 X-ray diffraction pattern of the as-deposited $\mathrm{Ni}_{3} \mathrm{~N}$ thin film.

rhombus like structure (Fig. 2(a)). The displayed fine morphology mainly depends on fabrication route and reaction conditions. The well observed 3D nano rhombus like structure may be favourable for effective electron transport and advance the efficiency of supercapacitors and DSSCs.

The constituent elemental composition of $\mathrm{Ni}_{3} \mathrm{~N}$ thin film was examined by EDS and the resultant spectrum is displayed in Fig. 2(b). These results confirm that the deposited film is composed of $\mathrm{Ni}$ and $\mathrm{N}$ elements with no other impurity peaks observed. The elemental mapping (Fig. 2(d and e)) of the $\mathrm{Ni}_{3} \mathrm{~N}$ thin film demonstrates that the atomic distribution of $\mathrm{Ni}$ and $\mathrm{N}$ is uniform and further proves the presence of $\mathrm{Ni}$ and $\mathrm{N}$ atoms in the $\mathrm{Ni}_{3} \mathrm{~N}$ thin film.

\subsection{Surface topography analysis}

Atomic force microscopy (AFM) is an important tool for examining surface topography and roughness parameters of the thin films. The AFM micrographs of $\mathrm{Ni}_{3} \mathrm{~N}$ films deposited on $\mathrm{Si}(100)$ substrates are shown in Fig. 3(a and b). The surface topography of the $\mathrm{Ni}_{3} \mathrm{~N}$ film shows that grains are uniformly distributed, without any fractures or voids in the film's surface. The surface topography provided by the AFM surface images is similar on comparison to FESEM results (FESEM image, Fig. 2(a)). The thin film surface roughness was also derived from AFM investigations. The root mean square roughness $\left(R_{\mathrm{q}}\right)$ and the average roughness $\left(R_{\mathrm{a}}\right)$ were found to be $68.4 \mathrm{~nm}$ and $56.2 \mathrm{~nm}$, respectively.

\subsection{Electrochemical measurements of the $\mathrm{Ni}_{3} \mathrm{~N}$ electrode}

In order to investigate the electrochemical supercapacitive performance of the as-prepared $\mathrm{Ni}_{3} \mathrm{~N}$ thin film electrodes, $\mathrm{CV}$ and GCD measurements were performed. Fig. 4(a) depicts the $\mathrm{CV}$ curves of $\mathrm{Ni}_{3} \mathrm{~N}$ using a three electrode cell configuration with $1 \mathrm{M} \mathrm{KOH}$ electrolyte. All of the CV curves were logged with a fixed potential of -0.1 to $0.5 \mathrm{~V}$ at a different scan rate ranging from 10 to $500 \mathrm{mV} \mathrm{s}^{-1}$. From the $\mathrm{CV}$ curves we observe two strong redox (anodic and cathodic) peaks, the anodic peaks are between 0.37 and $0.45 \mathrm{~V}$ with a similar trend for the cathodic peaks ranging from 0.08 to $0.2 \mathrm{~V}$, as displayed in Fig. 4(a), which 

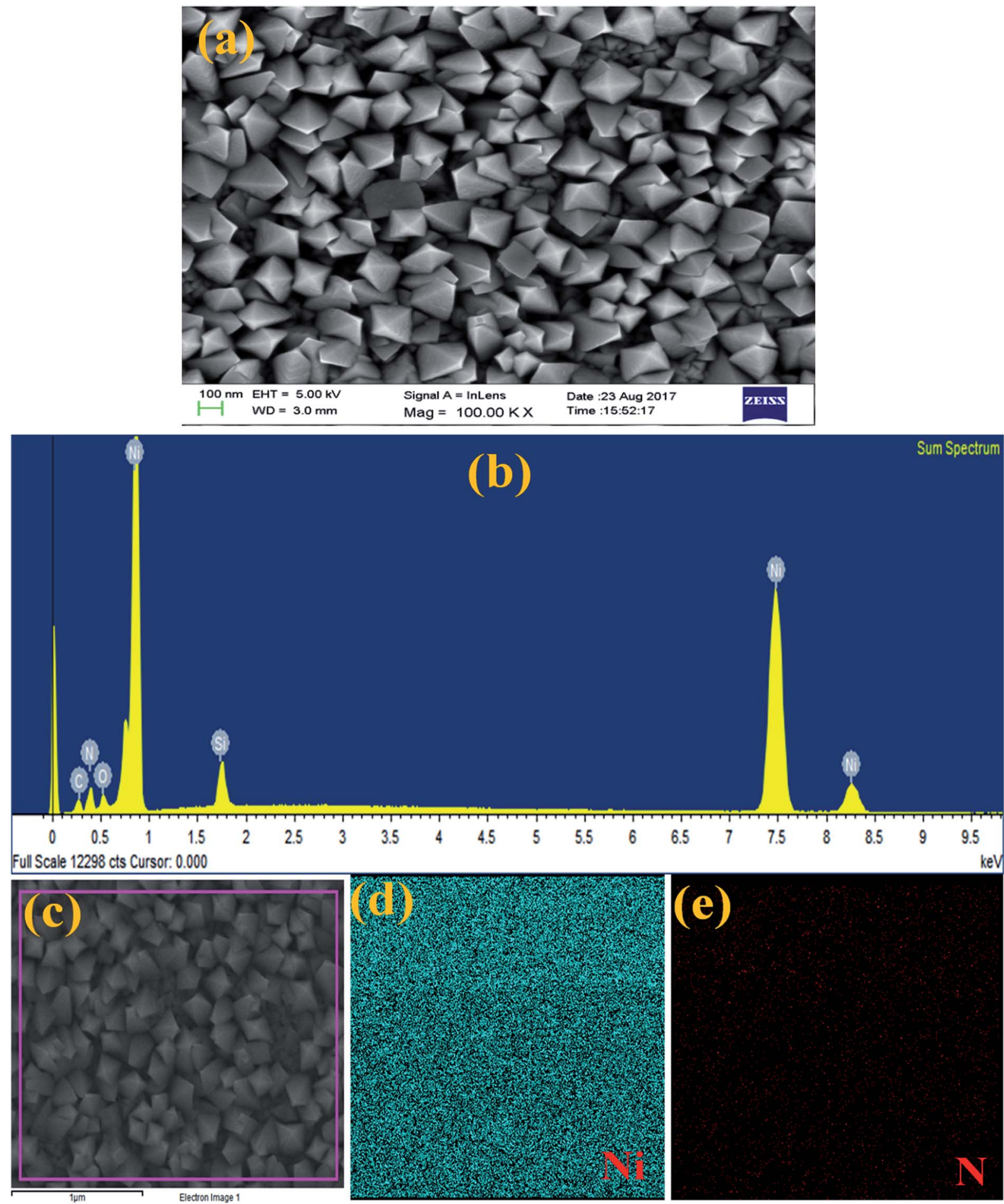

Fig. 2 (a) FESEM image of $\mathrm{Ni}_{3} \mathrm{~N}$ thin film, (b) EDS spectrum of $\mathrm{Ni}_{3} \mathrm{~N}$ thin film, (c) secondary electron image of $\mathrm{Ni}_{3} \mathrm{~N}$ thin film, and (d and e) EDS elemental mapping for $\mathrm{Ni}$ and $\mathrm{N}$, respectively.

is due to the reversible redox reactions and good rate capabilities of the $\mathrm{Ni}_{3} \mathrm{~N}$ electrode which is attributed to the capacitive characteristics produced by faradaic reactions. Hence the observed peak shifts mainly occur at a lower resistance, showing the pseudo-capacitive characteristic of the $\mathrm{Ni}_{3} \mathrm{~N}$ electrode. ${ }^{40,41}$ All of the $\mathrm{CV}$ curves show a similar response even when the scan rate is increased to $500 \mathrm{mV} \mathrm{s}^{-1}$, this could be caused by fast ion and charge mobility in the $\mathrm{KOH}$ electrolyte.

The areal capacitance of the $\mathrm{Ni}_{3} \mathrm{~N}$ electrode was derived from the integral area under the curve of the obtained CV curves using the following equation (eqn (1)); ${ }^{41}$ 

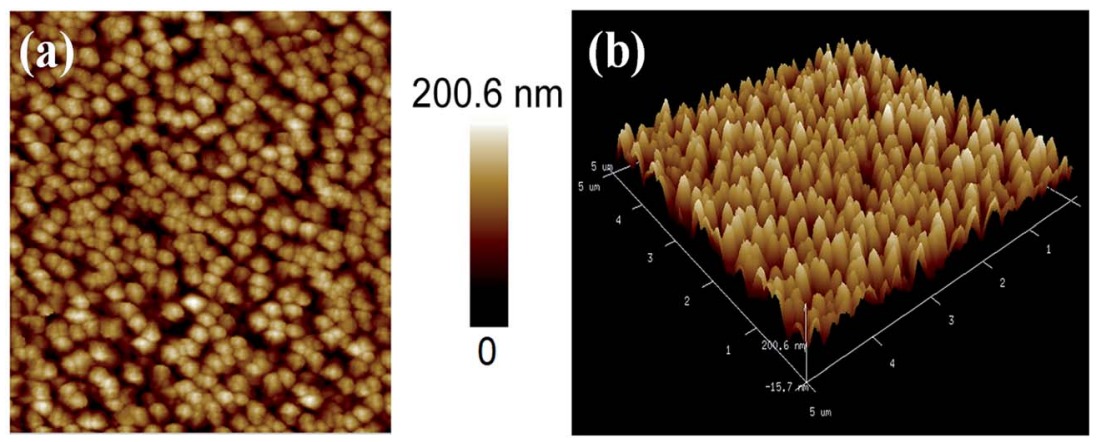

Fig. 3 ( $a$ and b) 2D and 3D AFM micrographs of $\mathrm{Ni}_{3} \mathrm{~N}$ thin film sputtered on Si substrate.

$$
\text { Areal capacitance }(C)=\frac{I}{W \times v \times \Delta V}\left(\mathrm{~F} \mathrm{~cm}^{-2}\right)
$$

where, $I$ represents the current in $\mathrm{mA}, v$ is the scan rate in $\mathrm{mV}$ $\mathrm{s}^{-1}, W$ is the geometric area of the working electrode $\left(1 \times 1 \mathrm{~cm}^{2}\right)$ and $\Delta V$ is the applied potential window in $V$. From $C V$ analysis, the highest areal and specific capacitances are $319.5 \mathrm{mF} \mathrm{cm}^{-2}$ and $285 \mathrm{~F} \mathrm{~g}^{-1}$ at a scan rate of $10 \mathrm{mV} \mathrm{s}^{-1}$. After increasing the scan rate to $500 \mathrm{mV} \mathrm{s}^{-1}$, areal and specific capacitances of 130 $\mathrm{mF} \mathrm{cm}{ }^{-2}$ and $6.8 \mathrm{~F} \mathrm{~g}^{-1}$ are obtained. From $\mathrm{CV}$ analysis, as the scan rate increases from 10 to $500 \mathrm{mV} \mathrm{s}^{-1}$ the areal capacitance and specific capacitance gradually decrease, as shown in
Fig. 4(b), this is because of the diffusion limit of the active electrolyte ions within the active surface of the electrode and, at high scan rates, the interfacial reaction kinetics. ${ }^{41}$ The calculated areal and specific capacitances with respect to the different scan rates is shown in Fig. 4(b). The cycling stability of the $\mathrm{Ni}_{3} \mathrm{~N}$ electrode was investigated by $\mathrm{CV}$ analysis at a fixed scan rate of $100 \mathrm{mV} \mathrm{s}^{-1}$ up to 2000 consecutive cycles, with the corresponding capacitance retention plot shown in Fig. 4(c), a capacitance retention of $93.7 \%$ was obtained after $2000 \mathrm{CV}$ cycles, suggesting that the as-prepared $\mathrm{Ni}_{3} \mathrm{~N}$ electrodes show excellent electrochemical stability. To further understand the
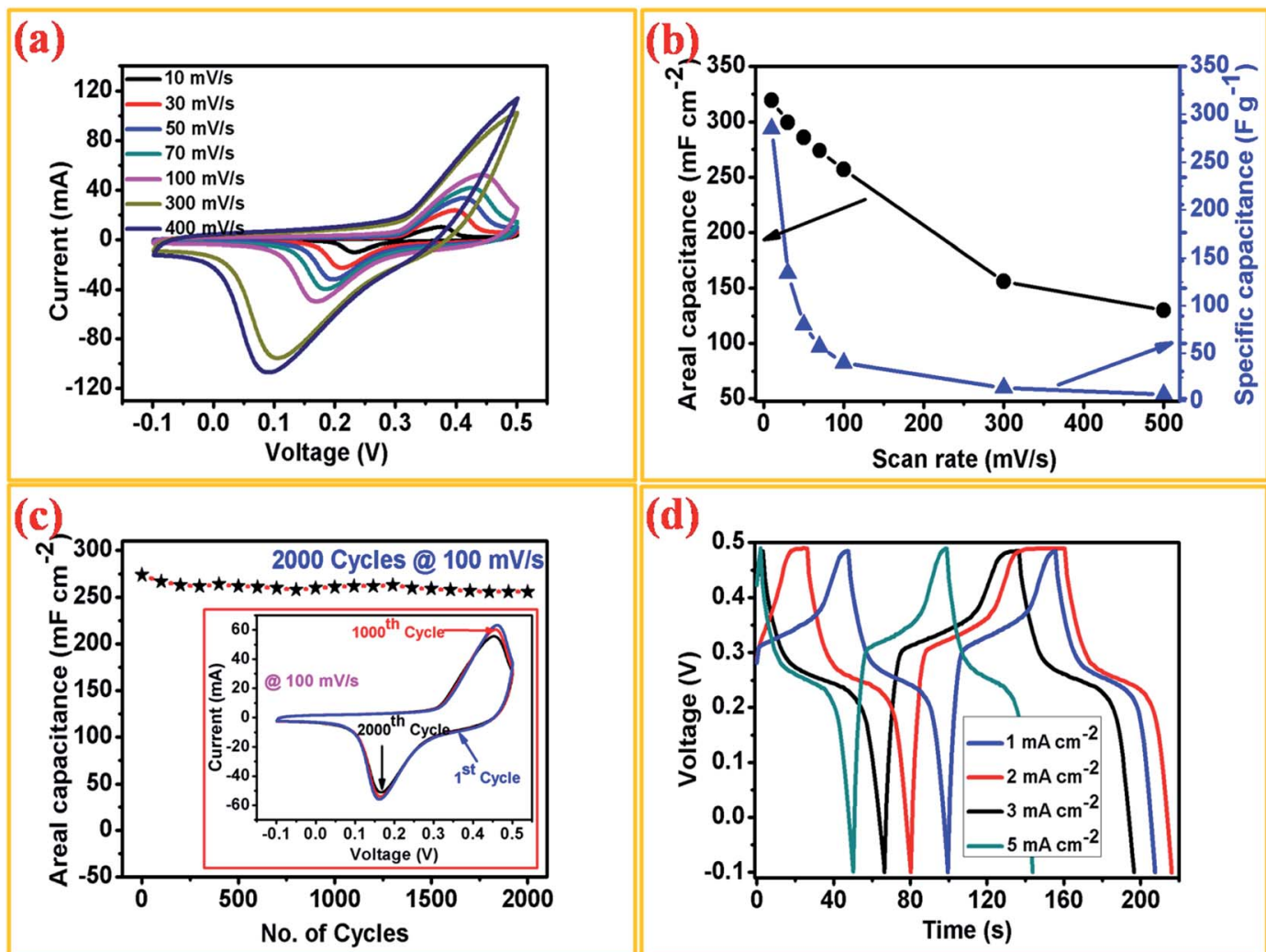

Fig. 4 Electrochemical measurements of the $\mathrm{Ni}_{3} \mathrm{~N}$ thin film electrode. (a) $\mathrm{CV}$ curves, (b) calculated areal capacitance and specific capacitance with respect to different scan rates, (c) the cycle performance of the Nis $\mathrm{N}$ electrode carried out at the scan rate of $100 \mathrm{mV} \mathrm{s}{ }^{-1}$ with calculated areal capacitance up to 2000 cycles (the inset figure represents the CV curves of the $1^{\text {st }}, 1000^{\text {th }}$ and $2000^{\text {th }}$ cycles) and (d) charge-discharge profiles taken at different current densities. 
supercapacitive performance of the $\mathrm{Ni}_{3} \mathrm{~N}$ electrode, galvanostatic charge-discharge (GCD) measurements were conducted at different current densities (1, 2, 3 and $5 \mathrm{~mA} \mathrm{~cm}^{-2}$ ). Fig. 4(d) shows the GCD curves of the $\mathrm{Ni}_{3} \mathrm{~N}$ electrode with respect to the different constant current densities. In these GCD profiles a slight curvature is observed, hence this result indicates the influence of both redox reactions (pseudocapacitor) and electrical double layer (EDLC) response which is similar to trends previously reported. ${ }^{\mathbf{4 0 , 4 2 - 4 4}}$

\subsection{Electrocatalytic activity of $\mathrm{Ni}_{3} \mathrm{~N}$ for triiodide reduction}

The electrocatalytic performance of $\mathrm{Ni}_{3} \mathrm{~N}$ CEs for the reduction of $\mathrm{I}_{3}{ }^{-}$to $\mathrm{I}^{-}$ions was observed by CV studies using three electrode configurations at a scan rate of $0.1 \mathrm{~V} \mathrm{~s}^{-1}$, with the resulting $\mathrm{CV}$ curve for the $\mathrm{I}^{-} / \mathrm{I}_{3}{ }^{-}$redox species depicted in Fig. 5(a). It should be noted that there are two pairs of redox peaks (Ox-1/Red-1, Ox-2/Red-2) for the $\mathrm{Ni}_{3} \mathrm{~N}$ electrodes. The left side pair (low potential region) of the redox peaks can be ascribed to the redox reaction shown in eqn (2), and the right side pair (high potential region) of the redox peaks can be associated with the redox reaction shown in eqn (3). ${ }^{\mathbf{4 5}, 46}$

$$
\begin{gathered}
\mathrm{I}_{3}{ }^{-}+2 \mathrm{e}^{-} \leftrightarrow 3 \mathrm{I}^{-} \\
3 \mathrm{I}_{2}+2 \mathrm{e}^{-} \leftrightarrow 2 \mathrm{I}_{3}{ }^{-}
\end{gathered}
$$
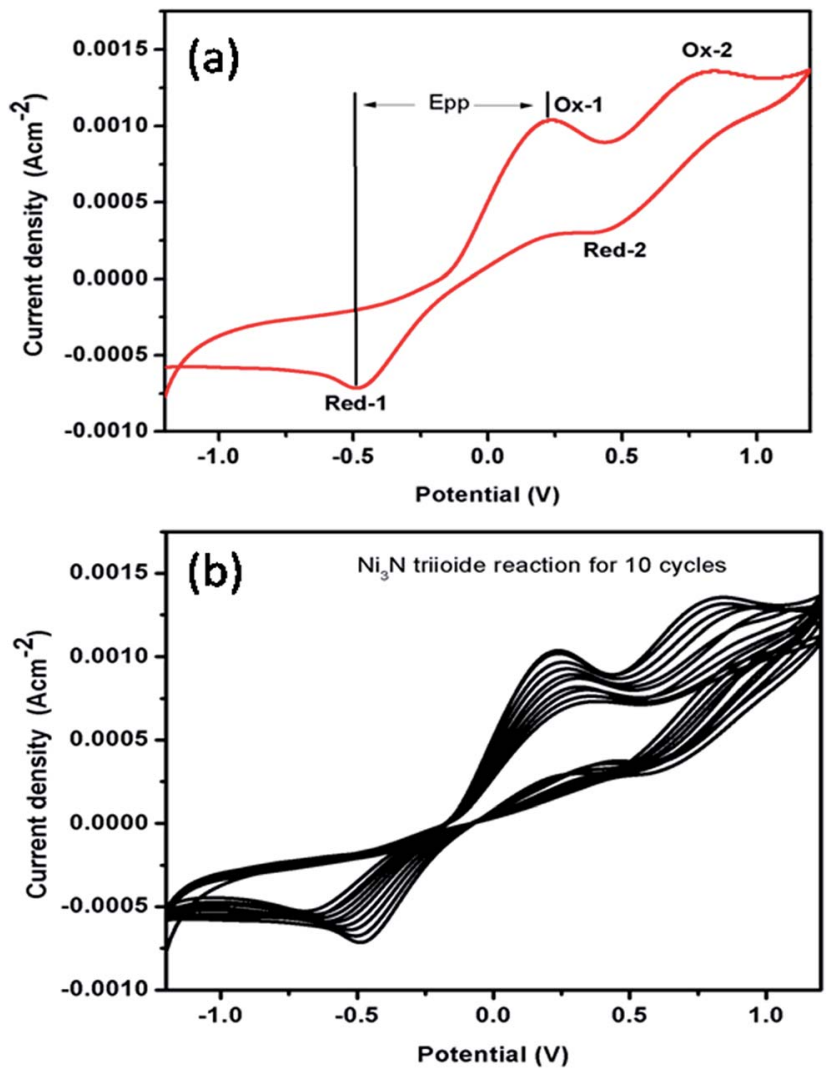

Fig. 5 (a) Cyclic voltammogram of the $\mathrm{Ni}_{3} \mathrm{~N} \mathrm{CE}$, and (b) stability test of the $\mathrm{Ni}_{3} \mathrm{~N} \mathrm{CE}$ at 10 cycles at a scan rate of $0.1 \mathrm{~V} \mathrm{~s}^{-1}$ in $10 \mathrm{mM} \mathrm{Lil}, 1 \mathrm{mMI}_{2}$ and $0.1 \mathrm{M} \mathrm{LiClO}_{4}$ as the supporting electrolyte in acetonitrile.
The $\mathrm{Ni}_{3} \mathrm{~N}$ electrode $\mathrm{CV}$ curve profile is similar in shape to that of a conventional platinum electrode reported in a previous report, ${ }^{45}$ which indicates a similar electrocatalytic activity for $\mathrm{Ni}_{3} \mathrm{~N}$ in a I${ }^{-} / \mathrm{I}_{3}{ }^{-}$redox system. The redox peaks, Ox-1 and Red-1, are the focus of our investigation in light of the fact that the CE is accountable for the electrocatalytic $\mathrm{I}_{3}{ }^{-}$reduction in DSSCs. ${ }^{47,48}$ The peak current density and the peak-to-peak separation $\left(E_{\mathrm{PP}}\right)$ are two vital factors for assessing the electrocatalytic performances of a CE. A higher $I_{\mathrm{PC}}$ implies a quicker reaction rate while a lower $E_{\mathrm{PP}}$ implies a smaller over-potential and enhanced electrocatalytic behaviour for $\mathrm{I}^{-} / \mathrm{I}_{3}{ }^{-}$redox reactions. Hence, a higher $I_{\mathrm{PC}}$ and a lower $E_{\mathrm{PP}}$ are advantageous for a $\mathrm{Ni}_{3} \mathrm{~N}$ CE to accomplish good electrocatalytic activity.

Furthermore, the electrocatalytic stability of a catalyst towards the reduction of $\mathrm{I}_{3}{ }^{-}$to $\mathrm{I}^{-}$ions is an important parameter for possible DSSC applications. To examine the electrocatalytic stability of the fabricated $\mathrm{Ni}_{3} \mathrm{~N}$ electrode, the electrocatalytic test was repeated for $\mathrm{I}_{3}{ }^{-}$reduction and the obtained results are depicted in Fig. 5(b). It should be noted that after 10 runs, the electrocatalytic activity of the $\mathrm{Ni}_{3} \mathrm{~N}$ electrode was mostly maintained at that of its initial run, demonstrating a good electrocatalytic stability.

\subsection{Photovoltaic performance of the DSSCs}

Fig. 6 reveals the $J-V$ characteristics of the DSSC with NiN CEs in E1 and E2 based ionic liquid electrolytes. The photovoltaic parameter performances are tabulated in Table 1. The DSSC with methoxypropionitrile (MPN) based electrolyte (E1) exhibits a lower conversion efficiency $(\eta)$ of $1.96 \%$ compared to acetonitrile (AcN) electrolyte (E2) of $\eta=2.88 \%$. This lower conversion performance is affected by poor fill factors and is strongly associated with the inferior electrocatalytic activity of $\mathrm{Ni}_{3} \mathrm{~N}$ CEs in iodide redox electrolyte. The poor short-circuit current density and fill factor of $\mathrm{Ni}_{3} \mathrm{~N}$ CEs are reflected in its performance. Nevertheless, the $J_{\mathrm{sc}}$ of the fabricated test device is

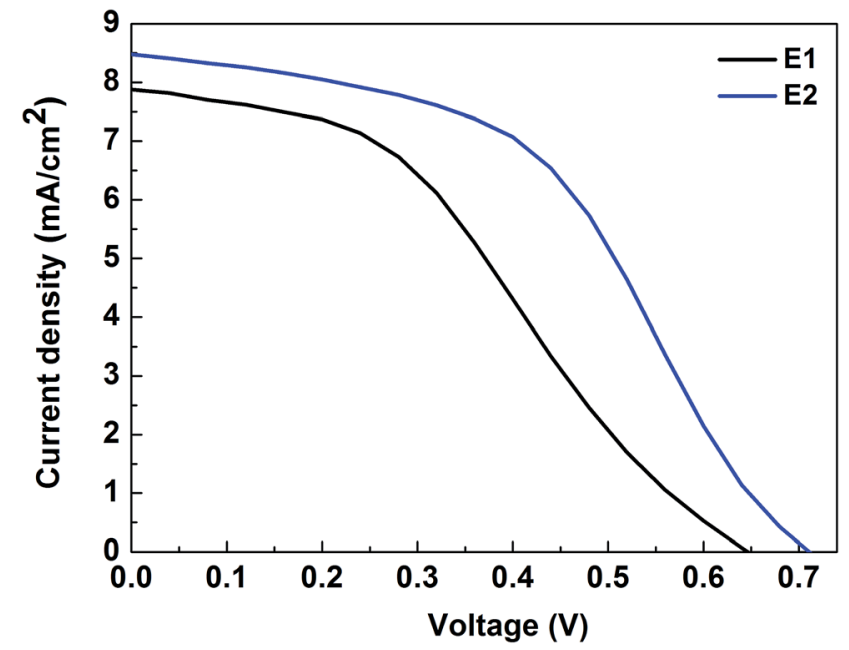

Fig. 6 Photocurrent density-voltage $(J-V)$ characteristic performance of open test devices. 
Table 1 Photovoltaic performance parameters of open test devices

\begin{tabular}{lllll}
\hline Electrolytes & $V_{\text {oc }}(\mathrm{V})$ & $J_{\text {sc }}\left(\mathrm{mA} \mathrm{cm}^{-2}\right)$ & FF & $\eta(\%)$ \\
\hline E1 & 0.65 & 7.87 & 0.39 & 1.96 \\
E2 & 0.71 & 8.47 & 0.47 & 2.88
\end{tabular}

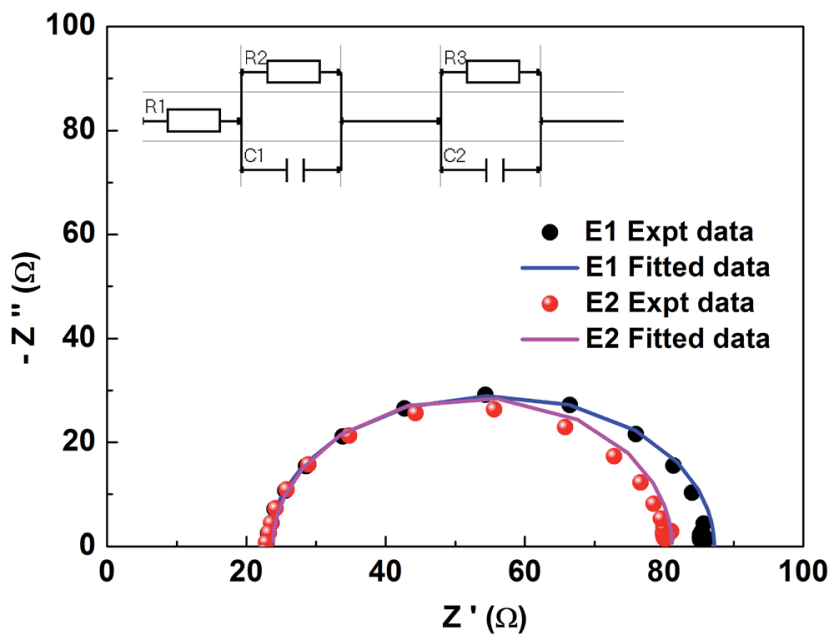

Fig. 7 EIS study performance of dummy cells with E1, E2 electrolytes.

higher in E1 electrolyte which is mainly due to the volatile AcN based solvent. Increased short-circuit current density $\left(J_{\mathrm{sc}}\right)$ and fill factor are reflected in an increased conversion efficiency with E1 compared to E2 which may be due to higher migration and penetration of AcN electrolyte into porous $\mathrm{TiO}_{2}$ and the higher conductivity nature of the AcN solvent compared to MPN.

The test device performance accorded well with EIS studies. An impedance spectrum was recorded for the fabricated DSSC devices with $\mathrm{Ni}_{3} \mathrm{~N}$ CEs in the two different electrolytes (E1 and E2). The EIS measurements were performed under light using a COMPACTSTAT. The Nyquist plots of the electrodes are presented in Fig. 7, and the equivalent circuit model is fitted, comprising $R_{\mathrm{S}}$ and $R_{\mathrm{CT}}$. The series resistance $\left(R_{\mathrm{S}}\right)$ which, due to contact resistance of $\mathrm{Ni}_{3} \mathrm{~N}$ with the FTO plate, and charge transfer resistances $R_{\mathrm{CT} 1}$ and $R_{\mathrm{CT} 2}$, signifies interfacial charge transfer resistances at the CE/electrolyte interface for an $\mathrm{I}^{-} / \mathrm{I}_{3}{ }^{-}$ redox reaction and the photoelectrode $(\mathrm{PE}) /$ electrolyte interface (i.e. impedance at the electrolyte/electrode interface). These resistances, which were obtained after fitting the impedance spectra well with IVIUMSOFT software, are tabulated in Table 2.

Table 2 EIS parameters of open dummy test cells in electrolytes E1 and E2

\begin{tabular}{lcc}
\hline Parameter & $\mathrm{E} 1$ & $\mathrm{E} 2$ \\
\hline$R_{\mathrm{S}}=R_{1}(\Omega)$ & 23.8 & 23.2 \\
$R_{\mathrm{CT} 1}=R_{2}(\mathrm{k} \Omega)$ & 68.1 & 30.6 \\
$R_{\mathrm{CT} 2}=R_{3}(\mathrm{k} \Omega)$ & 57.3 & 33.4 \\
$C_{1}(\mu \mathrm{F})$ & 4.35 & 2.08 \\
$C_{2}(\mu \mathrm{F})$ & 1.55 & 4.76
\end{tabular}

The lower resistance values observed for E2 electrolyte are reflected in the device performances.

In the present work, the device performance of $\mathrm{Ni}_{3} \mathrm{~N}$ CEs with an iodide based redox couple has been investigated. Further studies examining the conversion performance of these CEs with other redox couples may be worthwhile.

\section{Conclusions}

In conclusion, $3 \mathrm{D}$ nano rhombus $\mathrm{Ni}_{3} \mathrm{~N}$ thin films were prepared using a reactive $\mathrm{RF}$ magnetron sputtering technique. The asdeposited $\mathrm{Ni}_{3} \mathrm{~N}$ thin films were characterized by XRD, FESEM, AFM and EDS analysis. Subsequently, the as-deposited $3 \mathrm{D}$ nano rhombus $\mathrm{Ni}_{3} \mathrm{~N}$ thin films were evaluated as active electrode materials in SCs and as a platinum free, low cost $\mathrm{CE}$ in DSSCs. The electrochemical SC behaviour of the $\mathrm{Ni}_{3} \mathrm{~N}$ electrode was examined by $\mathrm{CV}$ and GCD. It demonstrated an areal capacitance value of $319.5 \mathrm{mF} \mathrm{cm} \mathrm{cm}^{-2}$ at a lower scan rate of $10 \mathrm{mV} \mathrm{s}^{-1}$. Interestingly; the fabricated DSSCs with $\mathrm{Ni}_{3} \mathrm{~N}$ CEs achieved a power energy conversion efficiency of $2.88 \%$ with a $V_{\mathrm{oc}}$ of $0.71 \mathrm{~V}, J_{\mathrm{sc}}$ of $8.47 \mathrm{~mA} \mathrm{~cm} \mathrm{~cm}^{-2}$ and $\mathrm{FF}$ of 0.47 . As a result, this $3 \mathrm{D}$ nano rhombus $\mathrm{Ni}_{3} \mathrm{~N}$ showed an enhanced specific capacitance with excellent stability and high electrocatalytic activity as an efficient CE for DSSCs. These results suggest a potential application of $3 \mathrm{D}$ nano rhombus $\mathrm{Ni}_{3} \mathrm{~N}$ thin films in electrochemical energy storage and conversion devices.

\section{Conflicts of interest}

There are no conflicts to declare.

\section{Acknowledgements}

The authors are grateful to the Deanship of Scientific Research, King Saud University for funding through Vice Deanship of Scientific Research Chairs.

\section{References}

1 C. Zarfl, A. E. Lumsdon, J. Berlekamp, L. Tydecks and K. Tockner, Aquat. Sci., 2015, 77, 161-170.

2 J. G. Chen, Surf. Sci. Rep., 1997, 30, 1-152.

3 S. Thomas, T. Deepak, G. Anjusree, T. Arun, S. V. Nair and A. S. Nair, J. Mater. Chem. A, 2014, 2, 4474-4490.

4 W. Hou, Y. Xiao and G. Han, Angew. Chem., Int. Ed., 2017, 56, 9146-9150.

5 Y. Xiao, J. Wu, J. Lin, G. Yue, J. Lin, M. Huang, Y. Huang, Z. Lan and L. Fan, J. Mater. Chem. A, 2013, 1, 13885-13889.

6 G. R. Li, F. Wang, Q. W. Jiang, X. P. Gao and P. W. Shen, Angew. Chem., Int. Ed., 2010, 49, 3653-3656.

7 A. K. Das, S. Sahoo, P. Arunachalam, S. Zhang and J. J. Shim, RSC Adv., 2016, 6, 107057-107064.

8 P. Arunachalam, S. Zhang, T. Abe, M. Komura, T. Iyoda and K. Nagai, Appl. Catal., B, 2016, 193, 240-247.

9 T. Kitamura, M. Maitani, M. Matsuda, Y. Wada and S. Yanagida, Chem. Lett., 2001, 30, 1054-1055. 
$10 \mathrm{~W}$. Hong, Y. Xu, G. Lu, C. Li and G. Shi, Electrochem. Commun., 2008, 10, 1555-1558.

11 Y. Xiao, J. Y. Lin, S. Y. Tai, S. W. Chou, G. Yue and J. Wu, J. Mater. Chem., 2012, 22, 19919-19925.

12 Y. Xiao, G. Han, Y. Li, M. Li and Y. Chang, J. Mater. Chem. A, 2014, 2, 3452-3460.

13 A. Malathi, P. Arunachalam, A. N. Grace, J. Madhavan and A. M. Al-Mayouf, Appl. Surf. Sci., 2017, 412, 85-95.

14 M. A. Ghanem, A. M. Al-Mayouf, P. Arunachalam and T. Abiti, Electrochim. Acta, 2016, 207, 177-186.

15 R. J. V. Michael, J. Theerthagiri, J. Madhavan, M. J. Umapathy and P. T. Manoharan, RSC Adv., 2015, 5, 30175-30186.

16 J. Theerthagiri, R. A. Senthil, A. Malathi, A. Selvi, J. Madhavan and M. Ashokkumar, RSC Adv., 2015, 5, 52718-52725.

17 J. Theerthagiri, R. A. Senthil, A. Priya, J. Madhavan, R. J. V. Michael and M. Ashokkumar, RSC Adv., 2014, 4, 38222-38229.

18 F. Gillot, J. Oró-Solé and M. R. Palacín, J. Mater. Chem., 2011, 21, 9997-10002.

19 S. Ge and J. F. Hartwig, Angew. Chem., Int. Ed., 2012, 51, 12837-12841.

20 M. P. Stewart, M. H. Ho, S. S. Wiese, M. L. Lindstrom, C. E. Thogerson, S. Raugei, R. M. Bullock and M. L. Helm, J. Am. Chem. Soc., 2013, 135, 6033-6046.

21 F. Alonso, P. Riente and M. Yus, Acc. Chem. Res., 2011, 44, 379-391.

22 X. Huang, E. Zhu, Y. Chen, Y. Li, C. Y. Chiu, Y. Xu, Z. Lin, X. Duan and Y. Huang, Adv. Mater., 2013, 25, 2974-2979.

23 Y. H. Chang, C. T. Lin, T. Y. Chen, C. L. Hsu, Y. H. Lee, W. Zhang, K. H. Wei and L. J. Li, Adv. Mater., 2013, 25, 756-760.

24 D. C. Dunand and P. Müllner, Adv. Mater., 2011, 23, 216-232.

25 J. Xie, S. Li, X. Zhang, J. Zhang, R. Wang, H. Zhang, B. Pan and Y. Xie, Chem. Sci., 2014, 5, 4615-4620.

26 B. Cao, G. M. Veith, J. C. Neuefeind, R. R. Adzic and P. G. Khalifah, J. Am. Chem. Soc., 2013, 135, 19186-19192.

27 Q. Jiang, G. Li, S. Liu and X. Gao, J. Phys. Chem. C, 2010, 114, 13397-13401.

28 Y. Dou, G. Li, J. Song and X. Gao, Phys. Chem. Chem. Phys., 2012, 14, 1339-1342.

29 W. F. Chen, K. Sasaki, C. Ma, A. I. Frenkel, N. Marinkovic, J. T. Muckerman, Y. Zhu and R. R. Adzic, Angew. Chem., Int. Ed., 2012, 51, 6131-6135.
30 M. Shalom, V. Molinari, D. Esposito, G. Clavel, D. Ressnig, C. Giordano and M. Antonietti, Adv. Mater., 2014, 26, 1272-1276.

31 Z. Xing, Q. Li, D. Wang, X. Yang and X. Sun, Electrochim. Acta, 2016, 191, 841-845.

32 F. Xie, H. Wu, J. Mou, D. Lin, C. Xu, C. Wu and X. Sun, J. Catal., 2017, 356, 165-172.

33 S. H. Park, J. Y. Kim, J. W. Lim, J. Shin, J. W. Choi and Y. E. Sung, Meet. Abstr., 2011, 37.

34 Y. Yu, W. Gao, Z. Shen, Q. Zheng, H. Wu, X. Wang, W. Song and K. Ding, J. Mater. Chem. A, 2015, 3, 16633-16641.

35 M. S. Balogun, Y. Zeng, W. Qiu, Y. Luo, A. Onasanya, T. K. Olaniyi and Y. Tong, J. Mater. Chem. A, 2016, 4, 98449849.

36 S. Sarkar, P. Howli, B. Das, N. S. Das, M. Samanta, G. C. Das and K. K. Chattopadhyay, ACS Appl. Mater. Interfaces, 2017, 9, 22652-22664.

37 R. Rajeswari, K. Susmitha, C. K. Jayasankar, M. Raghavender and L. Giribabu, Sol. Energy, 2017, 157, 956-965.

38 T. Rajesh Kumar, P. Prabukanthan, G. Harichandran, J. Theerthagiri, T. Tatarchuk, T. Maiyalagan, G. Maia and M. Bououdina, J. Solid State Electrochem., 2018, 1-11.

39 G. Durai, P. Kuppusami and K. Viswanathan, J. Mater. Sci.: Mater. Electron., 2018, 29(3), 2051-2058.

40 K. W. Park, B. K. Na, B. W. Cho, S. M. Park and K. C. Roh, Phys. Chem. Chem. Phys., 2013, 15, 17626-17635.

41 P. Gaikar, S. P. Pawar, R. S. Mane, M. Nuashad and D. V. Shinde, RSC Adv., 2016, 6, 112589-112593.

42 F. I. Dar, K. R. Moonoosawmy and M. Es-Souni, Nanoscale Res. Lett., 2013, 8, 363.

43 K. Thiagarajan, J. Theerthagiri, R. A. Senthil, P. Arunachalam, J. Madhavan and M. Ghanem, J. Solid State Electrochem., 2018, 22, 527-536.

44 J. Theerthagiri, K. Thiagarajan, B. Senthilkumar, Z. Khan, R. A. Senthil, P. Arunachalam, J. Madhavan and M. Ashokkumar, ChemistrySelect, 2017, 2, 201-210.

45 J. Theerthagiri, R. A. Senthil, M. H. Buraidah, J. Madhavan and A. K. Arof, J. Mater. Chem. A, 2016, 4, 16119-16127.

46 J. Theerthagiri, R. A. Senthil, M. H. Buraidah, K. Amarsingh Bhabu, J. Madhavan and A. K. Arof, Ionics, 2017, 23, 10171025.

47 J. Theerthagiri, R. A. Senthil, M. H. Buraidah, J. Madhavan and A. K. Arof, J. Solid State Chem., 2016, 238, 113-120.

48 S. Prasad, D. Durairaj, M. S. AlSalhi, J. Theerthagiri, P. Arunachalam and G. Durai, Energies, 2018, 11, 281, DOI: 10.3390/en11020281. 